Antonio Carlos Rodríguez, Miriam Pérez-Mateos, Mercedes Careche, Isabel Sánchez-Alonso, María Isabel Escribano, Pedro Dimas Sanz and Laura Otero*

\title{
Evaluation of the effects of weak oscillating magnetic fields applied during freezing on systems of different complexity
}

https://doi.org/10.1515/ijfe-2019-0178

Received June 11, 2019; accepted February 26, 2020; published online April 22, 2020

Abstract: The effects of weak oscillating magnetic fields (OMFs $\leq 7 \mathrm{mT}$ at $50 \mathrm{~Hz}$ ) on freezing were studied in three systems of different complexity. To do so, ferric chloride solutions, lactate dehydrogenase (LDH), and minced hake muscle experimentally infected with Anisakis L3 were frozen with and without OMF application. OMFs did not affect freezing kinetics of either ferric chloride solutions or minced hake muscle. LDH activity, Anisakis mortality, and water-holding capacity of the hake muscle after thawing were not affected by OMF either. Further studies are needed to evaluate the effectiveness of stronger OMFs in a wider frequency range.

Keywords: Anisakis; fish muscle; freezing kinetics; lactate dehydrogenase; oscillating magnetic fields.

\section{Introduction}

Even though freezing is a widely used technique to preserve biological materials such as food, cells, or tissues, it still presents several areas of improvement (control of ice crystallization, strategies to minimize freeze damage, efficient cold generation, maintenance of the cold supply chain, or environmental issues, among others). From the last decade, oscillating magnetic fields (OMFs) are being explored due to their potential positive effect on freezing, since it has been claimed that they could hinder ice nucleation and extend supercooling. In this way, they

*Corresponding author: Laura Otero, Instituto de Ciencia y Tecnología de Alimentos y Nutrición (ICTAN-CSIC), c/ José Antonio Novais, 10, 28040 Madrid, Spain, E-mail: l.otero@ictan.csic.es. https://orcid. org/0000-0003-1636-3263

Antonio Carlos Rodríguez, Miriam Pérez-Mateos, Mercedes Careche, Isabel Sánchez-Alonso, María Isabel Escribano and Pedro Dimas Sanz: Instituto de Ciencia y Tecnología de Alimentos y Nutrición (ICTAN-CSIC), c/ José Antonio Novais, 10, 28040 Madrid, Spain could enhance the generation of tiny crystals and prevent cell destruction, preserving the quality of the product intact after thawing [1-3]. Surprisingly, in spite of the number of existing patents, there is no unanimity among the scientific community on the potential goodness of this new technology. Thus, the extremely low strength of the frequently applied OMFs in commercial freezers (about 0.03-1.95 mT in CAS or 'Cells Alive System' freezers [4, 5], for example) casts doubt on the effects that these weak OMFs can have on a substance with a low magnetic susceptibility, such as water [6]. For this reason, it is necessary to evaluate magnetic effects not only in water but also in other molecules or systems that are usually present in biological materials and could potentially be affected by this technology. Moreover, to assess the effects of OMFs, attention should be focused on both the freezing process, by analyzing freezing kinetics, and on the product characteristics after thawing.

Among the systems to be studied, those containing transition metals such as $\mathrm{Fe}, \mathrm{Ni}$, or $\mathrm{Co}$ are of special interest due to their significant magnetic response [7]. OMFs should also be tested on freeze-sensitive systems in which any freezing improvement could be of great interest. In this sense, protein instability in aqueous solutions is a major difficulty and conventional freezing is not always a suitable solution. Thus, for example, lactate dehydrogenase (LDH) is a thermolabile enzyme that undergoes significant deterioration during freezing-thawing processes $[8,9]$. Slow freezing protocols combined with fast thawing rates and the use of cryoprotectants such as serum albumin are frequently used to improve LDH viability, but with moderate results [9]. Different authors have shown that the application of high-frequency electromagnetic fields at room temperature has non-thermal effects on macromolecules, proteins and enzymes [10-14] and, in particular, Vojisavljevic, Pirogova [11, 15] showed that LDH activity could be modulated by electromagnetic waves in the microwave frequency range. However, to the best of our knowledge, no data exist on the effect of low-frequency OMFs on LDH activity.

Even though commercial electromagnetic freezers have been mainly developed for the food industry, the 
effects of OMFs on food products are not well-known. Despite that, many companies already offer food products, especially fish, frozen in OMF freezers at significantly higher prices. This technology would be particularly interesting in the mitigation of the risk posed by fish infected with Anisakis simplex larvae in the third stage (L3), a parasite nematode that can infect humans when they consume raw or undercooked parasitized fish or cephalopods, since one of the most effective ways to avoid Anisakis L3 infection in humans is by freezing. EU Regulation [16] obliges food business operators to freeze fish that is to be consumed raw or after light culinary treatments for, at least, $24 \mathrm{~h}$ at a maximum temperature of $-20^{\circ} \mathrm{C}$ or, for $15 \mathrm{~h}$, at $-35^{\circ} \mathrm{C}$ or below. This, in practice, covers a wide range of conditions in terms of e. g., freezing rate, time, or temperature which can have an impact on the characteristics of fish muscle and, therefore, on its quality as food [17-20]. Therefore, effective methods to inactivate parasites in conditions that preserve the characteristics of the muscle are of high interest so that both quality and safety are fulfilled with the subsequent beneficial effects for the consumer.

However, Anisakis L3 are moderately freezing tolerant $[21,22]$ and this could pose a problem for the application of OMF freezing for inactivation of these nematodes. Thus, there are examples of living cells such as erythrocytes [23] or stem cells [24, 25] that render better survival results after OMF freezing than after conventional freezing. Until now, it has not been proven whether OMF would increase survival of Anisakis L3 during freezing which, irrespective of the potential beneficial effects on the quality of the muscle, would preclude the use of this technology in the particular application of EU regulation [16].

The objective of this work is to contribute to the current discussion on the application of OMFs during freezing by studying its effect on systems of different complexity. To do so, we studied: a) freezing kinetics in a ferric chloride solution, b) cryoprotection of the freezelabile enzyme lactate dehydrogenase (LDH), and c) the viability of Anisakis L3 and the water-holding capacity (WHC) of hake muscle experimentally infected with this nematode.

\section{Materials \& methods}

\subsection{Prototype of oscillating magnetic freezer}

A prototype of oscillating magnetic freezer was especially built to perform all the experiments described in this paper. It consisted of a
308-L domestic freezer (Koxka, Spain) in which an OMF generator and a fan (5958, ebm-papst Inc, Mulfingen, Germany) were located (Figure 1). The OMF generator was a custom-built electrical iron core inductor in series with a variable autotransformer able to produce OMFs of up to $7 \mathrm{mT}$ at $50 \mathrm{~Hz}$. The electrical circuit had a capacitor bank for power factor correction to compensate the inductive effect of the iron core. In addition, a $680-\Omega$ resistor, that worked only at low magnetic field strengths $(0.3-1.5 \mathrm{mT})$, was added in series with the rest of the circuit. This implied not only a reduction in the current flowing through the inductor, but also an increased precision of the selected current by the autotransformer knob. At the top part of the core, a sample holder was placed in the middle of the air gap $\left(10 \times 10 \times 4.2 \mathrm{~cm}^{3}\right)$. For the freezing experiments, the fan air speed and the freezer temperature were set at $0.24 \mathrm{~m} / \mathrm{s}$ and $-23 \pm 0.5{ }^{\circ} \mathrm{C}$, respectively. At these conditions, the heat transfer coefficient should be relatively low and this should make the identification of potential OMF effects easier than at faster freezing rates that could mask slight improvements.

\subsection{Freezing experiments in ferric chloride solutions}

Before each experiment, $20 \mathrm{~mL}$ of freshly prepared $3.6 \mathrm{mM} \mathrm{FeCl}_{3}$ solution in $0.1 \mathrm{M} \mathrm{HCl}$ was located in a glass vial (diameter $=2.3 \mathrm{~cm}$, height $=5.1 \mathrm{~cm}$ ). The sample was then placed inside the freezer and frozen with or without OMF application. Four levels of field strength $(0.3,0.8,1.5$, and $7 \mathrm{mT})$ at $50 \mathrm{~Hz}$ were tested. These OMF strengths were selected because they cover the strength range usually applied in commercial CAS freezers $(0.03-1.95 \mathrm{mT})$ and also a 10-fold larger level. All the experiments were performed in triplicate.

In each of the freezing experiments, the temperature was measured at the center of the sample by a fiber optic temperature probe (T1, Neoptix Inc, Québec City, Canada). Another fiber optic probe was employed to record the freezer temperature during the experiments. Both temperature measurements were registered every $5 \mathrm{~s}$ by a signal conditioner (Reflex, Neoptix Inc, Québec City, Canada) controlled by the software OptiLink-II (Neoptix Inc, Québec City, Canada). Freezing experiments were considered ended when the sample center reached $-20^{\circ} \mathrm{C}$.

2.2.1 Freezing kinetics: Freezing curves were analyzed to obtain some relevant parameters of the freezing process: the precooling rate, $V_{p}{ }^{\circ}$ $\mathrm{C} / \mathrm{min}$ ), defined as the slope of the time-temperature curve in the interval between $20^{\circ} \mathrm{C}$ and $8^{\circ} \mathrm{C}$; the supercooling degree, $\Delta T\left({ }^{\circ} \mathrm{C}\right)$, defined as the difference between the freezing point of the sample and the temperature at which nucleation occurred; the phase transition time,

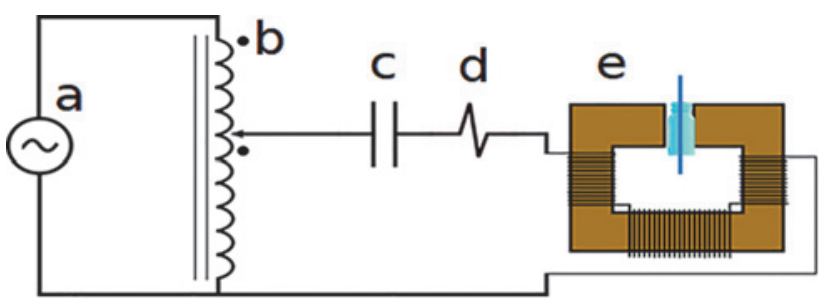

Figure 1: Oscillating magnetic field generator. Electric components: (a) the mains; (b) variable autotransformer; (c) capacitor bank; (d) resistor; (e) iron core inductor. 
$t_{\mathrm{pt}}(\min )$, defined as the time needed after nucleation to reach a temperature $0.5^{\circ} \mathrm{C}$ below the freezing point; the tempering rate, $V_{\mathrm{t}}\left({ }^{\circ} \mathrm{C} /\right.$ $\mathrm{min})$, defined as the slope of the time-temperature curve in the interval between $-5^{\circ} \mathrm{C}$ and $-15^{\circ} \mathrm{C}$; and the total freezing time, $t_{\mathrm{tf}}(\mathrm{min})$, defined as the time elapsed from the starting of the freezing experiment until the sample temperature reached $-20^{\circ} \mathrm{C}$.

\subsection{Freezing experiments in lactate dehydrogenase}

Lactate dehydrogenase type V-S from rabbit muscle (LDH, EC 1.1.1.23, Sigma, St. Louis, MO, USA) was used.

In each freezing experiment, six plastic Eppendorf tubes $(1.5 \mathrm{~mL})$, containing $100 \mu \mathrm{L}$ of enzyme solution $(8 \mu \mathrm{g} / \mathrm{mL}$ in $20 \mathrm{mM}$ potassium phosphate buffer, $\mathrm{pH}$ 7.5), were hung from the sample holder and placed at the center of the iron core inductor. Then the samples were frozen with $(7 \mathrm{mT} / 50 \mathrm{~Hz})$ or without OMF application. Immediately after freezing, the samples were thawed at room temperature for $5 \mathrm{~min}$ and subjected to a new freezing-thawing cycle at the same conditions before measuring LDH activity. Control experiments with samples frozen with liquid nitrogen $\left(-196^{\circ} \mathrm{C}, 30 \mathrm{~s}\right)$ were also performed for comparison.

2.3.1 LDH enzyme activity: Following the method of Goñi et al. [26], the residual enzyme activity was measured based on the conversion of pyruvate to lactate with concomitant conversion of equimolar amounts of $\mathrm{NADH}$ to $\mathrm{NAD}^{+}$. $\mathrm{LDH}$ enzymatic activity was determined in aliquots of $4 \mu \mathrm{L}$ in a final volume of $250 \mu \mathrm{L}$ of the reaction assay buffer (80 mM Tris- $\mathrm{HCl} \mathrm{pH}$ 7.5, $100 \mathrm{mM} \mathrm{KCl,} 2 \mathrm{mM}$ pyruvate and $0.15 \mathrm{mM}$ $\mathrm{NADH})$. $\mathrm{NAD}^{+}$production was monitored as the decrease of absorbance at $340 \mathrm{~nm}$ for $3.5 \mathrm{~min}$ at $25^{\circ} \mathrm{C}$ using a plate reader spectrophotometer (Synergy Mx, BioTek Instruments Inc., Winooski, VT, USA). The activity was measured in triplicate and the data are presented as the percentage of the LDH activity relative to the unfrozen controls.

\subsection{Freezing experiments in minced hake experimentally infected with Anisakis L3}

Two batches of hake (Merluccius merluccius L.) captured in North-East Atlantic Ocean, FAO fishing area 27 division VIIj, were purchased from a local fishmonger in February 2015 and June 2016 and arrived in the laboratory 7 and 9 days after catch, respectively. For each trial, five individuals were inspected and any visible Anisakis larva was taken out from the muscle. Then, the samples were grinded in a meat mincer machine ( $3 \mathrm{~mm}$ diameter hole), packaged, and stored at $4{ }^{\circ} \mathrm{C}$ until needed. Two batches of live Anisakis L3 from heavily infected ovaries and viscera of hake were obtained from the central market in Madrid in February 2015 and June 2016, respectively. Once in the laboratory, the larvae were taken out from the tissues, cleaned with $0.85 \% \mathrm{NaCl}$ solution, pooled in groups of 50 , and stored in $10 \mathrm{~mL} 0.85 \% \mathrm{NaCl}$ at $4{ }^{\circ} \mathrm{C}$ until use.

In each freezing experiment, 10 live Anisakis L3 dispersed in $77 \mathrm{~g}$ minced hake were disposed in triplicate into Petri dishes $(\phi=9 \mathrm{~cm}$, height $=1.2 \mathrm{~cm}$ ) and hung from the sample holder at the center of the iron core generator. The samples were then frozen either with $(7 \mathrm{mT} /$ $50 \mathrm{~Hz}$ ) or without OMF application. The temperature during experiments was measured at the center of the sample by a T-type thermocouple and recorded every second by a data acquisition system (DAQMaster MW100, Yokogawa, Tokyo, Japan). Freezing experiments were ended when the sample center reached $-20^{\circ} \mathrm{C}$. All the freezing experiments were performed in triplicate and, due to the length of each freezing assay (i. e., $2 \mathrm{~h}$ ), conventional and OMF experiments were carried out in different days.

2.4.1 Viability of Anisakis L3: Frozen samples were taken out of the freezer and allowed to thaw at $4{ }^{\circ} \mathrm{C}$. The thawed larvae were recovered from the mince with tweezers under UV light (366 nm) since Anisakis L3 emit a bluish-white fluorescence after treatments such as freezing [27]. Recovered larvae were placed in $0.85 \% \mathrm{NaCl}$ and checked for mobility according to EFSA [28]. Those larvae which did not show any movement, spontaneously or by stimulation with tweezers, either just after thawing or after incubation at $37^{\circ} \mathrm{C}$ for $4 \mathrm{~h}$ in $0.85 \% \mathrm{NaCl}$, were considered dead.

2.4.2 Water-holding capacity: The WHC of the minced fish muscle was measured in the second experiment (June 2016) by using centrifugal force to remove the free and loosely bound water of the samples according to Sánchez-Alonso et al. [29]. WHC determinations were performed just before (control samples) and immediately after each freezing experiment. Moreover, additional WHC determinations were carried out after 2.5 years of frozen storage at $-80^{\circ} \mathrm{C}$. Results were expressed in \% water retained after centrifugation per water originally present in the sample. All the measurements were performed in each sample in triplicate.

\subsection{Statistical analysis}

The statistical analysis of the data was performed using the software IBM SPSS Statistics v. 22.0.0.1 for Windows (IBM Corp., Armonk, NY, USA). Homoscedasticity of the data was checked by the Levene's test. After a one-way analysis of variance (ANOVA), significant differences among means were determined by a Tukey-b multiple range test in those cases in which the prerequisite of homogeneity of variances was fulfilled. Otherwise, Tamhane's post hoc test was employed. When needed, a Student's $t$-test for independent samples was performed. The significance level was set at 5\%.

\section{Results and discussion}

\subsection{Effect of OMF on freezing kinetics}

Figure 2 depicts representative time-temperature curves obtained during freezing experiments of ferric chloride solutions with and without OMF application. The curves exhibited the three main steps of the freezing process: precooling, phase transition, and tempering. During the precooling step, the temperature of the $\mathrm{FeCl}_{3}$ solution decreased while sensible heat was removed. Table 1 shows no effect of OMFs on the precooling rate, $V_{\mathrm{p}}$, that means no effect of OMFs on the rate of heat removal.

Once the freezing point of the ferric chloride solution was reached, freezing did not occur immediately in most of the cases, but the samples used to supercool before 


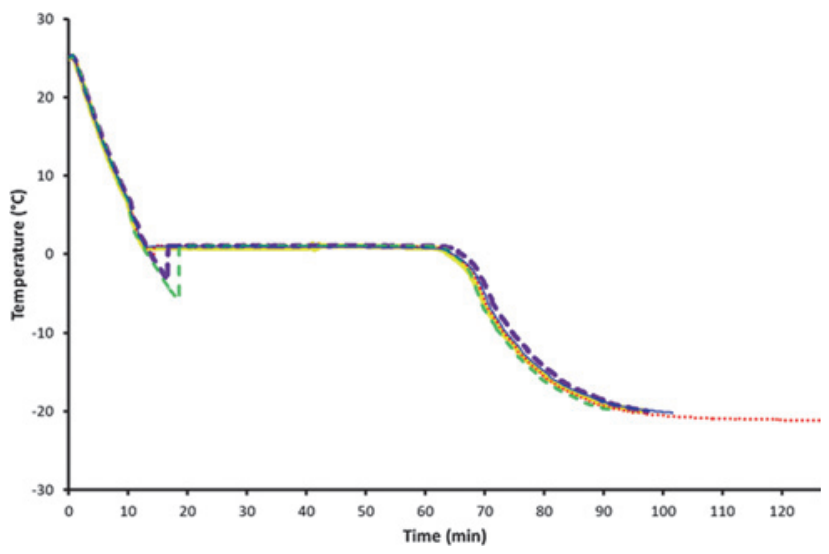

Figure 2: Freezing curves of the ferric chloride solutions at different field conditions: [ ] ] No magnetic field; [ $[\cdots \cdots$ ]: $0.3 \mathrm{mT}$ at $50 \mathrm{~Hz}$; $\square$ ]: $0.8 \mathrm{mT}$ at $50 \mathrm{~Hz}$; $\square]: 1.5 \mathrm{mT}$ at $50 \mathrm{~Hz}$, and [-]: $7 \mathrm{mT}$ at $50 \mathrm{~Hz}$.

nucleation. The data in Table 1 reveal that OMFs did not affect the extent of supercooling needed to initiate ice nucleation. As the rate of ice nucleation depends on the extent of supercooling, a similar quantity of ice nuclei should be expected in all the experiments. These results disagree with the patent claims and commercial advertisements of electromagnetic freezers that maintain that OMFs inhibit ice nucleation [30], but confirm previous results obtained by other authors in the literature. Thus, Watanabe, Kanesaka [31] reported that weak OMFs (0.5$10 \mathrm{mT}, 50 \mathrm{~Hz}$ ) did not affect supercooling of pure water and $\mathrm{NaCl}$ solutions, while James, Reitz [32] did not find any effect of OMFs $(0.1-0.4 \mathrm{mT}, 0-50 \mathrm{~Hz})$ on the extent of supercooling reached in garlic bulbs before freezing.

After nucleation, the temperature of the ferric chloride solution remained constant during the phase transition step. In this step, water molecules add to the ice nuclei previously formed while the latent heat of crystallization is removed. The data in Table 1 show no significant differences $(p>0.05)$ among the phase transition times registered in the freezing experiments with or without OMF application. These results corroborate that OMFs neither affected the rate of heat removal nor the rate of ice nucleation. Once all the water was converted to ice, the solution temperature decreased while sensible heat was removed during the tempering step. The results in Table 1 confirm again no effect of OMFs on the rate of heat removal and, thus, the total freezing times did not differ significantly among freezing experiments with or without OMF application. Similar results were found by Suzuki, Takeuchi [33] who froze several foods (radish, sweet potato, yellow tail, and tuna) while applying a $0.5-\mathrm{mT}$ OMF at $50 \mathrm{~Hz}$ and did not detect any effect of it on the freezing curves compared with control experiments without OMF application.

\subsection{Effect of OMF on the lactate dehydrogenase activity}

Freezing with liquid nitrogen resulted in a drastic inhibition of LDH activity with only $1.8 \pm 0.5 \%$ activity after two freezing-thawing cycles (Table 2). A lower loss of LDH activity occurred after freezing at $-23{ }^{\circ} \mathrm{C}$ in the laboratory prototype. This can be explained since fast cooling provides much more stress to proteins than a low cooling rate [9, 34]. Moreover, the detrimental effects on protein stability of a higher ice content after freezing in liquid nitrogen cannot be discarded.

No cryoprotective activity of OMF $(7 \mathrm{mT} / 50 \mathrm{~Hz})$ was detected at the low frequency applied in this paper (Table 2). By contrast, LDH activity was found to be affected

Table 2: Mean lactate dehydrogenase activity (\%) \pm standard error values before (not frozen) and after freezing at different conditions $(n=6)$.

\begin{tabular}{lr}
\hline Freezing procedure & LDH activity (\%) \\
\hline Not frozen & 100 \\
Liquid nitrogen $\left(-196^{\circ} \mathrm{C}\right)$ & $1.8 \pm 0.5$ \\
$0 \mathrm{mT}\left(-23^{\circ} \mathrm{C}\right)$ & $28.2 \pm 3.3$ \\
$7 \mathrm{mT}\left(-23^{\circ} \mathrm{C}\right)$ & $29.5 \pm 1.7$ \\
\hline
\end{tabular}

Table 1: Mean values \pm standard errors $(n=3)$ of relevant process parameters observed in freezing experiments of $\mathrm{FeCl}_{3}$ solutions with $(0.3$, $0.8,1.5$, or $7.0 \mathrm{mT}$ at $50 \mathrm{~Hz}$ ) or without $\mathrm{OMF}$ application. $V_{\mathrm{p}}$ : Precooling rate, $\Delta T$ : Extent of supercooling, $t_{\mathrm{pt}}$ : Phase transition time, $V_{\mathrm{t}}$ : Tempering rate, and $t_{\mathrm{ft}}$ : Total freezing time.

\begin{tabular}{|c|c|c|c|c|c|}
\hline & No OMF & $0.3 \mathrm{mT}$ & $0.8 \mathrm{mT}$ & $1.5 \mathrm{mT}$ & $7.0 \mathrm{mT}$ \\
\hline$V_{\mathrm{p}}\left({ }^{\circ} \mathrm{C} / \mathrm{min}\right)$ & $-1.8 \pm 0.1$ & $-1.8 \pm 0.1$ & $-1.8 \pm 0.1$ & $-1.9 \pm 0.1$ & $-1.8 \pm 0.0$ \\
\hline$\Delta T\left({ }^{\circ} \mathrm{C}\right)$ & $3.5 \pm 1.6$ & $1.2 \pm 0.3$ & $5.6 \pm 1.9$ & $3.3 \pm 2.0$ & $1.7 \pm 1.7$ \\
\hline$t_{\mathrm{pt}}(\min )$ & $51.1 \pm 1.3$ & $48.6 \pm 2.7$ & $50.0 \pm 2.4$ & $48.6 \pm 1.9$ & $50.5 \pm 1.2$ \\
\hline$V_{\mathrm{t}}\left({ }^{\circ} \mathrm{C} / \mathrm{min}\right)$ & $-0.9 \pm 0.1$ & $-0.9 \pm 0.1$ & $-0.9 \pm 0.0$ & $-1.0 \pm 0.0$ & $-1.0 \pm 0.0$ \\
\hline$t_{\mathrm{ft}}(\mathrm{min})$ & $92.5 \pm 3.0$ & $89.5 \pm 2.0$ & $93.1 \pm 2.5$ & $87.3 \pm 1.5$ & $89.0 \pm 0.8$ \\
\hline
\end{tabular}

No letters in the same row indicate no significant differences between means. 
in the microwave frequency region [15]. In this sense, Cosic, Pirogova [10] theoretically demonstrated that the effects of OMF on proteins depend on their frequencies and the amino acid number, and no effect would be expected below certain frequencies.

\subsection{Effect of OMF on viability of Anisakis L3 and water-holding capacity of experimentally infected minced hake muscle}

As in ferric chloride solution, no effect of OMF was observed on freezing kinetics of mince hake muscle (Figure 3). OMF failed to induce supercooling, as claimed by patents of electromagnetic freezers operating at similar frequency and strength range [30], in agreement with experiments in pork loin [35].

Conventional freezing under the assayed conditions rendered 100\% mortality of Anisakis L3 as expected. OMF freezing did not improve larvae survival and, therefore, this technology would be safe in terms of Anisakis L3 inactivation.

Changes in muscle characteristics were studied by means of WHC, a well-known indicator that has been reported to correlate with sensory attributes of fish muscle [36]. Depending on the processing conditions, this property can potentially decrease during freezing and mainly during frozen storage [19].

As explained in Materials and Methods, conventional and OMF freezing experiments had to be done in different days. Specifically, OMF experiments were performed 3 days after conventional ones. During this time, the WHC of the hake mince, stored at $4^{\circ} \mathrm{C}$, increased (Table 3) which

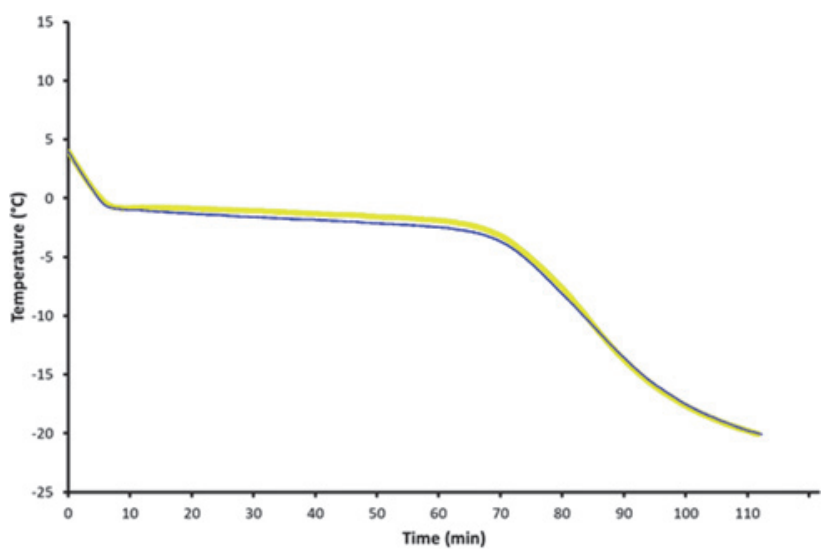

Figure 3: Freezing curve of the experimentally infected minced hake muscle at different field conditions: [_ ] ] No magnetic field and [-]: $7 \mathrm{mT}$ at $50 \mathrm{~Hz}$.
Table 3: Mean water-holding capacity $(\%) \pm$ standard error values in minced hake muscle $(n=3)$.

\begin{tabular}{llr}
\hline $\begin{array}{l}\text { Days at } 4^{\circ} \mathrm{C} \\
\text { after mincing }\end{array}$ & Sample & WHC (\%) \\
\hline 0 & Fresh & $62.29 \pm 2.34^{\mathrm{a}}$ \\
& Frozen $(0 \mathrm{mT})$ & $61.03 \pm 1.83^{\mathrm{a}}$ \\
& Frozen $(0 \mathrm{mT})$ and stored & $56.05 \pm 2.56^{\mathrm{b}}$ \\
& $\left(-80^{\circ} \mathrm{C}\right)$ for 2.5 years & \\
3 & Fresh & $68.31 \pm 3.76^{\mathrm{a}}$ \\
& Frozen $(0.7 \mathrm{mT})$ & $68.29 \pm 1.04^{\mathrm{a}}$ \\
& Frozen $(0.7 \mathrm{mT})$ and stored & $63.08 \pm 2.83^{\mathrm{b}}$ \\
& $\left(-80^{\circ} \mathrm{C}\right)$ for 2.5 years & \\
\hline
\end{tabular}

Different letters in each group of samples (i. e., 0 or 3 days after mincing) indicate significant differences between means.

can be attributed to the rise in $\mathrm{pH}$ occurring in post-mortem muscle [37].

No significant changes were observed, just after freezing, in the WHC values of either the conventionally or the OMF frozen samples as compared to their corresponding unfrozen controls (Table 3), although a nonsignificant decrease was found after conventional freezing in agreement with previous data in cod mince [38].

After 2.5 years of storage at $-80^{\circ} \mathrm{C}$, there was a significant loss of WHC in both conventionally and OMF frozen samples (i. e., 8.2 and 7.6\%, respectively) but the difference in this percentage loss was not significant. Erikson, Kjørsvik [4] did not find significant differences in WHC between freezing cod in commercial OMF and air blast freezers. Likewise, Rodríguez, James [35] and Otero, Pérez-Mateos [5] found no effect of OMF freezing on drip loss and waterholding capacity in pork loins and crab sticks, respectively. On the other hand, the data from freezing curves did not show differences in any parameter either, including supercooling degree. Taking both results into account, the possible beneficial effects of using this technology have not been demonstrated for this particular application.

\section{Conclusions}

Our study carried out in three systems of different complexity shows no advantages of the application of weak OMFs ( $\leq 7 \mathrm{mT}$ at $50 \mathrm{~Hz}$ ) during freezing either in freezing kinetics or in sample preservation.

The results on fish muscle infected with Anisakis L3 suggest that OMF freezing would be safe in terms of Anisakis inactivation. However, the potential benefits of using this technology in terms of the freezing kinetics or fish quality have not been demonstrated for this particular application. 
Further studies are needed to evaluate the effectiveness of stronger OMFs in a wider frequency range.

\section{UNE-EN ISO 9001 certification}

The Institute of Food Science, Technology and Nutrition (ICTAN-CSIC) has been certified since 2008 under UNE-EN ISO 9001 for "Management and execution of research projects and contracts in the area of Food Science and Technology and Nutrition" (certificate number ER-0366/2008).

Author contribution: All the authors have accepted responsibility for the entire content of this submitted manuscript and approved submission.

Research funding: This work has been supported by the Spanish MINECO under the project AGL2012-39756-C02-01 and by the European Union Seventh Framework Programme under the project EU PARASITE (GA 312068). A.C. Rodríguez has been supported by the MINECO under predoctoral grant BES-2013-065942.

Employment or leadership: None declared.

Honorarium: None declared.

Conflict of interest statement: The authors declare no conflicts of interest regarding this article.

\section{References}

1. Woo MW, Mujumdar AS. Effects of electric and magnetic field on freezing and possible relevance in freeze drying. Drying Technol 2010;28:433-43. https://doi.org/10.1080/07373930903202077.

2. Xanthakis E, Le Bail A, Havet M. Freezing combined with electrical and magnetic disturbances. In: Sun D-W, editor. Emerging Technologies for Food Processing, 2nd ed. Elsevier Ltd, Academic Press; 2014. https://doi.org/10.1016/B978-0-12-411479-1.00030-9.

3. Dalvi-Isfahan M, Hamdami N, Xanthakis E, Le-Bail A. Review on the control of ice nucleation by ultrasound waves, electric and magnetic fields. J Food Eng 2017;195:222-34. https://doi.org/10. 1016/j.jfoodeng.2016.10.001.

4. Erikson U, Kjørsvik E, Bardal T, Digre H, Schei M, Søreide TS, et al. Quality of Atlantic cod frozen in cell alive system, air-blast, and cold storage freezers. J Aquatic Food Prod T. 2016;25:1001-20. https://doi.org/10.1080/10498850.2015.1007542.

5. Otero L, Pérez-Mateos M, Rodríguez AC, Sanz PD. Electromagnetic freezing: Effects of weak oscillating magnetic fields on crab sticks. J Food Eng 2017;200:87-94. https://doi.org/10.1016/j.jfoodeng. 2016.12.018.

6. Otero L, Rodríguez AC, Pérez-Mateos M, Sanz PD. Effects of magnetic fields on freezing: Application to biological products. Compr Rev Food Sci F 2016;15:646-67. https://doi.org/10.1111/ 1541-4337.12202.

7. Hattori S, Watanabe M, Sasaki K, Yasuharu H. Magnetization of activated sludge by an external magnetic field. Biotechnol Lett 2002;24:65-9. https://doi.org/10.1023/A:1013869611352.
8. Aldén M, Magnusson A. Effect of temperature history on the freeze-thawing process and activity of $L D H$ formulations. Pharm Res 1997;14:426-30. https://doi.org/10.1023/A: 1012083029205.

9. Cao E, Chen Y, Cui Z, Foster P. Effect of freezing and thawing rates on denaturation of proteins in aqueous solutions. Biotechnol Bioeng 2003;82:684-90. https://doi.org/10.1002/bit.10612.

10. Cosic I, Pirogova E, Vojisavljevic V, Fang Q, editors. Frequency dependence of macromolecular activation. Proceedings of the 5th IASTED International Conference on Biomedical Engineering, BioMED; 2007.

11. Vojisavljevic V, Pirogova E, Cosic I. The effect of electromagnetic radiation $(550-850 \mathrm{~nm})$ on 1-Lactate dehydrogenase kinetics. Int J Radiat Biol 2007;83:221-30. https://doi.org/10.1080/ 09553000701227565.

12. Vojisavljevic V, Pirogova E, Cosic I, editors. Review of studies on modulating enzyme activity by low intensity electromagnetic radiation. Proceedings of the Annual International Conference of the IEEE Engineering in Medicine and Biology Society; 2010.

13. Beyer C, Christen P, Jelesarov I, Fröhlich J. Experimental system for real-time assessment of potential changes in protein conformation induced by electromagnetic fields. Bioelectromagnetics 2013;34:419-28. https://doi.org/10.1002/ bem.21795.

14. Beyer C, Christen P, Jelesarov I, Fröhlich J. Real-time assessment of possible electromagnetic-field-induced changes in protein conformation and thermal stability. Bioelectromagnetics 2014; 35:470-8. https://doi.org/10.1002/bem.21865.

15. Vojisavljevic V, Pirogova E, Cosic I. Low intensity microwave radiation as modulator of the 1-lactate dehydrogenase activity. Med Biol Eng Comput 2011;49:793-9. https://doi.org/10.1007/ s11517-010-0690-2.

16. European Commission. Commission Regulation (EU) No 1276/ 2011 of 8 December 2011 amending Annex III to Regulation (EC) No $853 / 2004$ of the European Parliament and of the Council as regards the treatment to kill viable parasites in fishery products for human consumption. 2011. https://data.europa.eu/eli/reg/ 2011/1276/oj.

17. Careche M, Carmona P, Sánchez-Alonso I. Monitoring the time and temperature history of frozen hake (Merluccius merluccius, L.) muscle by FTIR spectroscopy of the lipid fraction. Food Bioprocess Tech 2015;8:112-9. https://doi.org/10.1007/s11947014-1386-7.

18. Sánchez-Valencia J, Sánchez-Alonso I, Martinez I, Careche M. Estimation of frozen storage time or temperature by kinetic modeling of the Kramer shear resistance and water holding capacity (WHC) of hake (Merluccius merluccius, L.) muscle. J Food Eng 2014; 120:37-43. https://doi.org/10.1016/j.jfoodeng.2013.07.012.

19. Sánchez-Valencia J, Sánchez-Alonso I, Martínez I, Careche M. Lowfield nuclear magnetic resonance of proton ('H LF NMR) relaxometry for monitoring the time and temperature history of frozen hake (Merluccius merluccius, L.) muscle. Food Bioprocess Tech 2015;8: 2137-45. https://doi.org/10.1007/s11947-015-1569-x.

20. Sánchez-Alonso I, Moreno P, Careche M. Low field nuclear magnetic resonance (LF-NMR) relaxometry in hake (Merluccius merluccius, L.) muscle after different freezing and storage conditions. Food Chem 2014;153:250-7. https://doi.org/10. 1016/j.foodchem.2013.12.060.

21. Sánchez-Alonso I, Carballeda-Sangiao N, González-Muñoz M, Navas A, Arcos SC, Mendizábal A, et al. Pathogenic potential of 
Anisakis $\mathrm{L} 3$ after freezing in domestic freezers. Food Control 2018;84:61-9. https://doi.org/10.1016/j.foodcont.2017.07.010.

22. Wharton DA, Aalders 0 . The response of Anisakis larvae to freezing. J Helminthol 2002;76:363-8. https://doi.org/10.1079/ JOH2002149.

23. Lin CY, Wei PL, Chang WJ, Huang YK, Feng SW, Lin CT, et al. Slow freezing coupled static magnetic field exposure enhances cryopreservative efficiency - A study on human erythrocytes. Plos One 2013;8:e58988. https://doi.org/10.1371/journal.pone. 0058988.

24. Lin PY, Yang YC, Hung SH, Lee SY, Lee MS, Chu IM, et al. Cryopreservation of human embryonic stem cells by a programmed freezer with an oscillating magnetic field. Cryobiology 2013;66: 256-60. https://doi.org/10.1016/j.cryobiol.2013.02.061.

25. Shikata H, Kaku M, Kojima SI, Sumi H, Kojima ST, Yamamoto T, et al. The effect of magnetic field during freezing and thawing of rat bone marrow-derived mesenchymal stem cells. Cryobiology 2016;73:15-9. https://doi.org/10.1016/j.cryobiol.2016.06.006.

26. Goñi O, Sanchez-Ballesta MT, Merodio C, Escribano MI. Regulation of defense and cryoprotective proteins by high levels of $\mathrm{CO}_{2}$ in Annona fruit stored at chilling temperature. J Plant Physiol 2009; 166:246-58. https://doi.org/10.1016/j.jplph.2008.04.005.

27. Vidaček S, de las Heras C, Solas MT, Mendizábal A, RodríguezMahillo Al, Tejada M. Antigenicity and viability of Anisakis larvae infesting hake heated at different time-temperature conditions. J Food Prot 2010; 73:62-8. https://doi.org/10.4315/0362-028X73.1.62.

28. EFSA Panel on Biological Hazards (BIOHAZ). Scientific Opinion on risk assessment of parasites in fishery products. EFSA J 2010;8: 1543. https://doi.org/10.2903/j.efsa.2010.1543.

29. Sánchez-Alonso I, Careche M, Moreno P, González M, Medina I. Testing caffeic acid as a natural antioxidant in functional fishfibre restructured products. Food Sci Techn 2011;44:1149-55. https://doi.org/10.1016/j.lwt.2010.11.018.
30. Owada N, Kurita S. Method and apparatus for quick freezing. Patent EP 1135999 A1. 2001 26.09.2001.

31. Watanabe M, Kanesaka N, Masuda K, Suzuki T, editors. Effect of oscillating magnetic field on supercooling in food freezing. The 23rd IIR International Congress of Refrigeration: Refrigeration for sustainable development. Prague, Czech Republic; 2011 August. p. 21-26.

32. James C, Reitz B, James SJ. The freezing characteristics of garlic bulbs (Allium sativum L.) frozen conventionally or with the assistance of an oscillating weak magnetic field. Food Bioprocess Technol 2015;8:702-8. https://doi.org/10.1007/s11947-014-1438z.

33. Suzuki T, Takeuchi Y, Masuda K, Watanabe M, Shirakashi R, Fukuda $Y$, et al. Experimental investigation of effectiveness of magnetic field on food freezing process. Trans Japan Soc Refrig Air Conditioning Eng 2009;26:16.

34. Strambini GB, Gabellieri E. Proteins in frozen solutions: Evidence of ice-induced partial unfolding. Biophysical J 1996;70:971-6. https://doi.org/10.1016/S0006-3495(96)79640-6.

35. Rodríguez AC, James C, James SJ. Effects of weak oscillating magnetic fields on the freezing of pork loin. Food Bioprocess Technol 2017;10: 1615-21. https://doi.org/10.1007/s11947-017-1931-2.

36. Jensen HS, Jørgensen BM. A sensometric approach to cod-quality measurement. Food Qual Prefer 1997;8:403-7. https://doi.org/ 10.1016/S0950-3293(97)00029-3.

37. Rustad T. Muscle chemistry and the quality of wild and farmed cod. In: Huss HH, Jakobsen M, Liston J, editors. Quality Assurance in the Fish Industry. Developments in Food Science. 301992. p. 19-27.

38. Erikson U, Veliyulin E, Singstad TE, Aursand M. Salting and desalting of fresh and frozen-thawed cod (Gadus morhua) fillets: A comparative study using $23 \mathrm{Na} \mathrm{NMR}, 23 \mathrm{Na}$ MRI, low-field $1 \mathrm{H}$ NMR, and physicochemical analytical methods. J Food Sci 2004; 69: FEP107-FEP14. https://doi.org/10.1111/j.1365-2621.2004. tb13362.x. 